PontIFícIA UNIVERSIDADE CATÓLICA dO RIO DE JANEIRO

\begin{abstract}
A inserção dos autistas no mercado de trabalho carioca
\end{abstract}

Luiz Felipe de Meneses Yuan

Trabalho de Conclusão de Curso

CENTRO de CIÊNCIAS SOCIAIS - CCS

Departamento de AdMINISTRAÇÃo

Graduação em Administração de Empresas 
Luiz Felipe de Meneses Yuan

\section{A inserção dos autistas no mercado de trabalho carioca}

\section{Trabalho de Conclusão de Curso}

Trabalho de Conclusão de Curso, apresentado ao programa de graduação em Administração da PUC-Rio como requisito parcial para a obtenção do titulo de graduação em Administração.

Orientadora: Andréa Bittencourt

Rio de Janeiro 23 de novembro de 2017. 


\section{Agradecimentos}

Aos meus pais, Michelle e Ricardo, que me amaram de forma incondicional desde o meu primeiro dia de vida e que possibilitaram que estudasse numa faculdade renomada como a PUC-RIO.

Aos meus avós, Helena e Carlos, que estão comigo em todos os momentos, bons e ruins. Tenho a sorte de ter neles mais uma mãe e pai.

Aos meus irmãos Rafaela, Maria Carolina e Guilherme, por tornarem a minha vida mais completa e feliz.

À minha orientadora, Andrea Bittencourt, pela compreensão e disponibilidade para a conclusão deste trabalho final de curso.

E, acima de tudo, agradeço ao meu irmão Matheus de 12 anos, a pessoa mais especial dessa família e da minha vida, que abriu os meus olhos para o mundo autista e da luta que devo fazer enquanto cidadão e irmão para garantir que os seus direitos e de todos os autistas sejam garantidos. 


\section{Resumo}

Yuan, Luiz. Bittencourt, Andréa. A inserção dos autistas no mercado de trabalho carioca. Rio de Janeiro, 2017. 37 p. Trabalho de Conclusão de Curso - Departamento de Administração. Pontifícia Universidade Católica do Rio de Janeiro.

Este trabalho tem como objetivo analisar a inserção dos autistas no mercado de trabalho, procurando conhecer as peculiaridades de um indivíduo com TEA e quais os ganhos corporativos que uma empresa pode ter ao incorporar um funcionário autista em sua organização. Desta forma, a pesquisa se propõe a ter relatos das partes interessadas, analisando a adaptação dos autistas nas organizações, as relações com colegas de trabalho e a necessidade de especialização para inserção no mercado de trabalho.

Palavras chave: autista, mercado de trabalho, inserção, organização

\section{Abstract}

Yuan, Luiz. Bittencourt, Andréa. The insertion of the autistic in the labor market of Rio de Janeiro. Rio de Janeiro, 2017. 37 p. Final Paper Administration Department. Pontifícia Universidade Católica of Rio de Janeiro.

This work aims to anlyze the insertion of autistics in the labor market, seeking to know the peculiarities of an individual with ASD and what corporate gains a company may have by incorporating an autistic employee into their organization. In this way, the research proposes to have reports of the interested parties, analyzing the adaption of the autistic ones in the organizations, the relations with coworkers and need of specialization for insertion in the labor market.

Key-words: Autistic, labor market, insertion, organization 


\section{Sumário}

1. O tema e o problema de estudo

1.1. Introdução ao tema e ao problema do estudo

1.2. Objetivo do estudo $\underline{2}$

1.3. Objetivos intermediários do estudo $\underline{2}$

1.4. Delimitação e foco do estudo $\underline{3}$

1.5. Justificativa e relevância do estudo $\underline{3}$

2. Referencial Teórico $\underline{4}$

2.1. Conceituando o autismo $\underline{4}$

2.1.2. Classificação do autismo $\underline{6}$

2.2. Legislação $\underline{7}$

2.3. Diversidade no mercado de trabalho $\underline{9}$

2.4. Motivação de um organização contratar ou não um autista

3. Metodologia $\quad \underline{13}$

3.1 Tipo de pesquisa e método utilizado

3.2 Procedimentos e instrumentos de coleta de dados utilizados no estudo $\underline{14}$

3.3. Tratamento e análise dos dados coletados para o estudo

3.4. Limitações do Estudo

4. Resultados da pesquisa $\quad \underline{16}$

4.1. Os entrevistados $\underline{16}$

4.2. Resposta e análise $\quad \underline{17}$

4.2.1. Grupo $1 \quad \underline{17}$

4.2.1.1. Especialização da mão-de-obra $\quad \underline{17}$

4.2.1.2. Ambiente propiciado pela empresa $\underline{18}$

4.2.1.3. Relação com colegas de trabalho $\quad \underline{19}$

4.2.2. Grupo 2

4.2.2.1. Política de adaptação da empresa $\underline{20}$

4.2.2.2. Relação do profissional autista no ambiente de trabalho a partir da ótica da organização 
4.2.2.3. Avaliação do impacto do profissional autista na organização

4.2.3. Grupo 3

4.2.3.1 Diagnóstico do Transtorno do Espectro Autista $\underline{22}$

4.2.3.2. Acompanhamento do autista no mercado de trabalho $\underline{23}$

4.2.3.3. Adequação das empresas

5. Conclusões e contribuições do estudo 


\section{O tema e o problema de estudo}

\subsection{Introdução ao tema e ao problema do estudo}

Os portadores de deficiência sempre encontraram extrema dificuldade ao tentar a inserção ao mercado de trabalho, tanto que foi necessária a criação da chamada Lei de Cotas (Lei 8.213) em 1991 como uma forma de integração destes ao mundo corporativo. No caso dos portadores do Transtorno do Espectro Autista (TEA), a sua constante exclusão no mercado de trabalho, como comprovado pela National Autistic Society (2016) - apenas 12\% dos adultos autistas com alto grau de funcionamento trabalham em tempo integral -, fez com que também fossem incluídos na Lei de Cotas em 2012. O autismo é uma síndrome descoberta recentemente, o que acaba gerando profundo desconhecimento em relação à mesma (Amy, 1995), enfocando somente nas dificuldades sociais e de comunicação que estes indivíduos possuem.

O esforço para a inclusão dos deficientes, com enfoque nos autistas neste estudo, deve ser promovido da mesma forma que ocorreu com as diferentes raças, gêneros e orientação sexual, garantindo a pluralidade no trabalho. As organizações precisam estar preparadas a receber indivíduos que se relacionem de forma não convencional, compreendendo que isso faz parte daquele ser, mas que sua capacidade de realizar tarefas para as quais foi formado não estará comprometida, conseguindo muitas vezes trazer perspectivas diferentes para uma empresa, com seu olhar minucioso, detalhista.

Segundo Carvalho (1994), integração é um processo de incorporar física e socialmente dentro da sociedade as pessoas que estão segregadas e separadas por nós. Significa ser membro ativo da comunidade, vivendo onde outros vivem, vivendo com os outros e tendo os mesmos privilégios e direitos que os cidadãos não deficientes. Portanto, temos como dever cívico proporcionar a essas pessoas não somente os direitos e deveres enquanto cidadãos, mas também de equiparar as oportunidades de mercado entre pessoas não deficientes e deficientes.

Dessa forma, a seguinte questão será levantada ao longo do estudo: Qual é a importância de incluirmos os autistas no mercado de trabalho? 


\subsection{Objetivo do estudo}

O trabalho tem como objetivo identificar as possibilidades de inserção no mercado de trabalho dos portadores do Transtorno do Espectro Autista (TEA), quais os motivos para que uma empresa escolha contratar um autista, ou não, e como isso impacta direta e indiretamente na produtividade da mesma.

\subsection{Objetivos intermediários do estudo}

Para atingir o objetivo do estudo proposto existem algumas etapas que devem ser abordadas:

- Conceituar o autismo, quais são as suas peculiaridades, vantagens e desvantagens quando comparadas com pessoas não portadoras de deficiência.

- Descrever a classificação dos diferentes graus do Transtorno do Espectro Autista.

- Indicar o impacto da legislação brasileira nas vidas dos autistas

- Relacionar a Diversidade no mercado de trabalho

- Analisar quais são as vantagens e desvantagens da diversidade no mercado de trabalho advinda da inclusão de um portador da síndrome do autismo. 


\subsection{Delimitação e foco do estudo}

A síndrome do autismo possui diversos graus de severidade, havendo casos em que o indivíduo não está apto a fazer coisas básicas do cotidiano, e também há casos em que o portador da síndrome é um gênio em determinado assunto.

Sendo assim, este estudo volta-se mais especificamente para abordar os autistas com alto grau de funcionamento, que conseguiram desenvolver habilidades que os possibilitem viver de forma autônoma e foram capacitados a entrar no mercado de trabalho. É interessante aprofundar o conhecimento sobre os autistas, pelo fato de possuírem uma percepção ímpar sobre o mundo em que estão inseridos, trazendo uma perspectiva diferente da que estamos acostumados. Para efeitos de pesquisa, o estudo se delimita ao território da cidade do Rio de Janeiro de forma a trazer resultados mais precisos.

Embora relevante, o presente trabalho não pretende tratar da capacidade de inserção ao mercado de trabalho de outras síndromes existentes, evidenciando somente o processo dos portadores de autismo ao tentar a inserção no mundo corporativo.

\subsection{Justificativa e relevância do estudo}

As informações que este estudo pretende produzir podem se mostrar de interesse para os portadores de autismo, pois demonstrará quais são as suas possibilidades no mercado, o que eles têm de diferente em relação à mão-deobra comum e como podem se aproveitar disso.

Os resultados a serem alcançados também poderão ser úteis para as organizações, pelo fato de demonstrarem quais são as capacidades e limitações desses indivíduos, podendo encontrar perfis específicos para determinadas funções.

Acima de tudo, a maior relevância deste estudo é desmitificar a incapacidade de produção de trabalho dos autistas com alto grau de funcionamento, demonstrar que estão aptos a lidar com a demanda do mercado, conscientizando as empresas que a forma dessas pessoas de comunicação e de trabalho pode ser um pouco diferente do usual, mas que isso não deve ser 
tratado como um empecilho, e sim como uma forma de diversidade no trabalho, que nos dias de hoje é visto como um elemento essencial de sucesso. 


\section{Referencial Teórico}

Neste capítulo são apresentados e discutidos aspectos conceituais e estudos relacionados ao tema e estudo em investigação e que servirão de base para a análise realizada.

Esta seção está dividida em 3 partes que abordam, respectivamente, a conceituação do autismo para contextualizar o problema de estudo a partir da visão de Frith (1989), Sigman (1995) e Solomon (2013) e as classificações do Transtorno do Espectro Autista (TEA). Logo em seguida, é feita uma análise da legislação brasileira em relação aos autistas, e na terceira parte a importância da diversidade no mercado de trabalho aos olhos de Thomas e Ely (2002) referências na área, como se encontra a situação dos de empregabilidade dos autistas e o dever cívico da nossa sociedade perante as pessoas com habilidades diferentes

\subsection{Conceituando o autismo}

De acordo com Frith (1989), o TEA é uma deficiência mental específica, que afeta qualitativamente o indivíduo nas suas interações sociais recíprocas, na comunicação não verbal e verbal, na atividade imaginativa e se expressa por meio de um repertório restrito de atividades e interesses. O autista apresenta três características: dificuldade de relação interpessoal, no domínio da linguagem para a comunicação e apresenta um padrão repetitivo de comportamento. Este indivíduo pode passar pelas pessoas como se não as visse, pode não responder quando chamado, estabelecer algum tipo de contato, ainda mais se estiver entretido em uma atividade que de fato seja de seu interesse (SIGMAN et al., 1995). É importante ressaltar que não se trata de uma doença, mas sim de uma síndrome, pois é um conjunto de comportamentos e não uma entidade biológica conhecida (SOLOMON, 2013).

A capacidade de se relacionar com o mundo, de uma forma geral, é muito árdua para os autistas se comparada com as pessoas que não possuem essa síndrome. As organizações avaliam nos dias de hoje que uma boa capacidade 
de se relacionar é um ponto positivo, pois demonstra a aptidão de trabalhar em equipe, estar em um ambiente repleto de pessoas com as mais diferentes personalidades, capacidade de melhorar a produtividade dos colegas de trabalho, e até mesmo receber um feedback de forma natural, e é nesse ponto que os autistas necessitam de uma abordagem diferente por parte dos seus gestores e colegas de trabalho, é importante que haja a compreensão destes que os autistas possuem uma forma peculiar de socialização.

\subsubsection{Classificação do autismo}

O estereótipo criado pela sociedade em relação aos autistas é aquela pessoa isolada, distante do mundo que a rodeia e com uma repetição incessável de movimentos com as mãos, cabeça. Entretanto, nem todos os autistas apresentam estas características, podendo haver variação do comportamento dos indivíduos que se enquadram no diagnóstico de Transtorno do Espectro Autista. De acordo com a edição mais recente do Manual de Diagnóstico e Estatística das Perturbações Mentais (ASSOCIAÇÃO PSIQUIÁTRICA AMERICANA, 2013) o TEA pode ser subdivido nos seguintes grupos: autismo clássico, autismo de baixo ou alto funcionamento, síndrome de Asperger, transtorno invasivo do desenvolvimento sem outra especificação (PDD-NOS), síndrome de Rett e transtorno desintegrativo da infância.

- Autismo clássico: Na maioria dos casos o diagnóstico ocorre antes dos 3 anos de idade, o indivíduo possui dificuldades de socialização, comunicação e apresenta comportamentos repetitivos.

- Autismo de baixo ou alto funcionamento: Enquanto o autista de baixo funcionamento possui um QI abaixo da média e sintomas mais profundos das características citadas dos autistas clássicos, o de alto funcionamento possui um QI normal e sintomas mais brandos. 
- Síndrome de Asperger: Esta síndrome também se caracteriza pela dificuldade do indivíduo nas relações interpessoais e interesse obsessivo sobre um limitado gama de assunto. No entanto, não existe atraso na linguagem ou no desenvolvimento cognitivo.

- PDD-NOS: Suas principais características são os desafios significativos de desenvolvimento da linguagem e habilidade social. A pessoa diagnosticado com o PDD-NOS pode possuir uma ou até mais de uma característica referente ao autismo, mas não possui todas as características. Exemplo: $O$ indivíduo pode ter sérios problemas de fala, mas não apresentar nenhum comportamento repetitivo.

- Síndrome de Rett: De acordo com Alysson Muotri (2007), a criança com essa síndrome nasce normal, sem nenhum problema aparente até mais ou menos o primeiro ano de vida. Contudo, a partir dessa idade nota-se uma regressão mental acompanhada de dificuldade motoras e respiratórias, tremores e frequentes ataques epiléticos. Além disso, fica restrito ao uso de cadeira de rodas e têm ausência de comunicação verbal.

- Transtorno desintegrativo da infância: A criança com este transtorno possui um desenvolvimento normal de habilidade social e comunicação até aos 2 anos de idade. Após esta idade, a criança passa a apresentar déficits em áreas que antes pareciam estar em pleno desenvolvimento, como: habilidades sociais, motora, linguagem e comportamento.

\subsection{Legislação}

A Lei Berenice Piana foi um grande passo para a criação de uma política de inclusão e tratamento dos autistas. Após um longo e duro processo, como 
retratado por Ulisses Costa (2013) em seu livro "Autismo no Brasil, um grande desafio!", as milhares de famílias que são afetadas por esta síndrome conseguiram que essa lei chegasse ao congresso e por fim viram a Lei $n^{0}$ 12.764 ser sancionada pela então presidente Dilma Roussef.

Dentre os sete artigos presentes na Lei, é importante destacar dois deles: Art. 1

§ 2ํㅜ A pessoa com transtorno do espectro autista é considerada pessoa com deficiência, para todos os efeitos legais.

A inclusão dos autistas no grupo de deficientes representa uma esperança para os mesmos e suas famílias, pois o amparo legal no que se diz respeito à inclusão, tratamento multidisciplinar e, acima de tudo, inclusão no mercado de trabalho. Como previsto na Lei Brasileira de Inclusão No 13.146, de 6 de julho de 2015:

Art. 34․ A pessoa com deficiência tem direito ao trabalho de sua livre escolha e aceitação, em ambiente acessível e inclusivo, em igualdade de oportunidade com as demais pessoas.

§ $1^{\circ}$ As pessoas jurídicas de direito público, privado ou de qualquer natureza são obrigadas a garantir ambiente de trabalho acessíveis e inclusivos.

§ $3^{\circ}$ É vedada restrição ao trabalho da pessoa com deficiência e qualquer discriminação em razão de sua condição, inclusive nas etapas de recrutamento, seleção, contratação, admissão, exames admissional e periódico, permanência no emprego, ascensão profissional e reabilitação profissional, bem como exigência de aptidão plena.

A empresa que tiver 100 ou mais empregados é obrigado por lei a preencher $2 \%$ a $5 \%$ dos seus cargos com beneficiários reabilitados ou pessoas portadoras de deficiência. Seguindo a proporção: 200 empregados (2\%), 201 a $500(3 \%), 501$ a $1000(4 \%)$ e 1001 em diante (5\%).

O segundo artigo a ser destacado na lei Berenice Piana é:

\section{Art.2 ${ }^{\circ}$}

V - o estímulo à inserção da pessoa com transtorno do espectro autista no mercado de trabalho, observadas as peculiaridades da deficiência e as disposições da Lei no 8.069, de 13 de julho de 1990 (Estatuto da Criança e do Adolescente). 
Os últimos anos, no que concerne à esfera legislativa, o movimento autista obteve grande vitórias. Seja para incluir o indivíduo na sociedade, oferecendo atividades multidisciplinares que são o pilar para o desenvolvimento do autista, ou garantindo o espaço dos mesmos no mercado de trabalho, contudo, na prática este não tem sido o resultado averiguado junto aos autistas e suas famílias. Para ilustrar, uma reportagem do portal de notícias G1 (15/02/2014) mostra a dona de casa Joana Darlí, moradora da cidade de Porangatu, interior do estado de Góias, lutando para conseguir tratamento para o seu filho de três anos diagnosticado com autismo. Como a renda mensal da família é de um salário mínimo, Joana não tem condições de pagar pelo tratamento do seu filho em uma instituição privada, tendo em vista que são valores fora de sua realidade, a sua última opção é o Estado, que por sua vez não possui um Caps (Centro de Atenção Psicosocial) na cidade, resultando na falta de amparo por parte do governo ao menino previsto por lei.

Este caso é a luta de uma das milhares de mães que passam pelo mesmo desamparo no Brasil, demonstrando a urgência de traduzir essa vitória legislativa para o mundo real. Ari Ne'eman, autista e um dos escolhidos por Barack Obama para o Conselho Nacional de Deficientes Americano, reforça a necessidade do apoio do governo, " Nós nunca dissemos que o autismo não representa uma deficiência, mas ele não representa uma doença. Dê aos indivíduos autistas as oportunidades educacionais e oportunidades de prosperar e ter sucesso nos seus próprios termos" (SOLOMON, 2013, p. 365)

\subsection{Diversidade no mercado de trabalho}

A inclusão dos autistas nas organizações faz parte do processo da diversidade no mercado de trabalho, como foi com o gênero, raça, orientação sexual, idade e cultura. Essa prática não pode ser mais vista como uma opção, mas sim obrigação para ser mais competitivo, é uma forma de adicionar valor à organização, trazendo múltiplas perspectivas, com cada pessoa contribuindo de forma única e ímpar, fazendo que o pensamento de grupo seja uma raridade na organização que adote um staff diversificado. Além disso, maior diversidade na força de trabalho aumenta a eficiência organizacional e, consequentemente, a 
produtividade, pois permite que a empresa tenha acesso a novos segmentos de mercado, gerando aumento da lucratividade (THOMAS E ELY, 2002).

De acordo com uma pesquisa realizada pela National Autistic Society, 12\% dos adultos autistas com alto grau de funcionamento possuem trabalho em tempo integral, por outro lado, um estudo publicado pela Journal of Autism and Devolopment Disorders (2014), 87,5\% dos autistas que recebem suporte para a inserção no mercado de trabalho conseguem emprego, contra $6,2 \%$ dos que não tem ajuda. Essa discrepância fez com que o secretário geral da ONU Ban Kimoon realizasse um "Call to Action" em 2014 no dia mundial de conscientização do autismo, afirmando que " Para medir o sucesso de nossas sociedades, devemos analisar como as pessoas com diferentes habilidades, incluindo pessoas com autismo, estão integradas como membros valiosos". Além disso, tocou diretamente no assunto do mercado de trabalho dos autistas, para Ban Kimoon o dia de conscientização do autismo é mais do que gerar entendimento, é um chamado para ação, convocando as pessoas para promover o progresso de programas educacionais, oportunidades de emprego, e outras ações que ajudem a tornar o nosso mundo mais inclusivo.

Algumas organizações estão dispostas a atender esse chamado, como é o caso da Specialsterne e da Geatte, que fazem a formação e inserção no mercado de trabalho de pessoas com TEA, oferecendo a capacitação técnica e na formação de habilidades sociolaboral, aprendendo aspectos relacionados ao comportamento na empresa, como se comunicar no ambiente de trabalho. Toda a formação feita pela Specialsterne é para o mercado de $\mathrm{TI}$, o que chamou interesse da SAP, gigante da tecnologia, a firmar um projeto de que nos próximos anos $1 \%$ dos empregados da empresa sejam autistas. Em entrevista à revista Exame (2016) a líder deste projeto no Brasil, Thais Catarino, afirma que os autistas possuem formas diferentes de pensar e enfrentar desafios o que agrega valor para companhia, gerando vantagem competitiva.

Temple Grandin, referência no ativismo do autismo e uma das primeiras pessoas com o TEA a retratar a experiência que é ter essa síndrome, defende que os autistas devem desenvolver habilidades de acordo com a sua capacidade "Você tem um garoto que adora geologia. Ora, em vez de desenvolver seu interesse para que ele entre numa carreira, os pais, os professores e terapeutas insistem no treinamento de habilidades sociais. $O$ treinamento de habilidades sociais é importante mesmo, mas não fique preso a isso a ponto de descuidar de suas aptidões" (SOLOMON, 2013, p. 392). Se a criança autista apresentar uma facilidade com números, com a criação de arte ou qualquer outra aptidão é 
muitíssimo importante fomentar essa habilidade, pois é uma forma de preparar desde a infância dessas pessoas a entrada no mercado de trabalho.

\subsection{Motivação de uma organização para contratar ou não um autista}

Algumas organizações começaram a olhar os autistas com alto grau de funcionamento com outros olhos, pois foram identificadas algumas características nessas pessoas que são difíceis de serem encontradas no mercado. De acordo com a reportagem "Autistas chegam ao mercado de trabalho", da revista ISTOÉ (09/11/2011), os autistas têm uma boa memória, uma mente muito bem estruturada, paixão por detalhes, bom faro para encontrar erros e perseverança para realizar atividades repetitivas, além disso possuem uma capacidade de abordar a adversidade de uma maneira distinta, o que os torna altamente atraentes como empregados para as empresas. As organizações não querem somente contratar autistas por conta da Lei de Cotas, mas sim pelo que podem prover com sua capacidade analítica. Grandes empresas como SAP, Microsoft e Siemens aderiram à contratação destes indivíduos como forma de vantagem competitiva.

Mesmo com a possibilidade de ganho de mão de obra, algumas organizações relutam em contratar os autistas pelo fato de ser importante a socialização em boa parte das funções, como visto na reportagem da Oi Educa (2014), momentos como horário de almoço ou até mesmo reunião de equipe pode ser um desafio para essas pessoas, pelo fato de haver a necessidade de socializar e isso ser uma dificuldade para as mesmas.

De acordo com Solomon (2013) todo autista possui um padrão singular de fragilidades e pontos fortes, podendo ser extremamente competente em um ponto e incompetente em outro. John Elder Robison, um ativista do movimento do autismo e autor de "Olhe nos meus olhos", demonstrou muitíssima competência no desenvolvimento de seu livro, mas tinha dificuldades em externar expressões humanas "Eu nem entendia o que significava olhar nos olhos de alguém. E, no entanto, ficava envergonhado porque as pessoas esperavam que eu o fizesse, e eu sabia disso, mas não o fazia. Quando fiquei 
mais velho, ensinei a mim mesmo a agir de modo 'normal'"'(2013, p.390). Mesmo que o autista tenha algum tipo de dificuldade na relação interpessoal, é papel da organização criar um ambiente que o mesmo se sinta à vontade e acolhido, apontando algum mentor para ajudá-lo nessa transição, e talvez, como John Elder, consiga desenvolver habilidades que o auxilie nas relações de trabalho. 


\section{Metodologia}

\subsection{Tipo de pesquisa e método utilizado}

Considerando-se objetivos de estudo deste trabalho, a pesquisa utilizada é a exploratória descritiva de natureza qualitativa. Segundo Vergara (2000) a pesquisa descritiva expõe as características de determinada população ou fenômeno, estabelece correlações entre variáveis e define sua natureza. Já no que se refere a pesquisa exploratória, Zikmund (2000) aponta que os estudos exploratórios, geralmente, são úteis para diagnosticar situações, explorar alternativas ou descobrir novas ideias. A associação dos métodos exploratórios e descritivos, objetivam uma melhor definição do problema, ao proporcionar intuições de solução, descrição de comportamentos de fenômenos, definição e classificação de fatos e variáveis (SALOMON, 2001, p.95).

De acordo com Gil (2008), por ser um tipo de pesquisa muito específica, quase sempre ela assume a forma de um estudo de caso, e segundo Yin (2001) o estudo de caso é uma investigação empírica que investiga um fenômeno contemporâneo, como o apresentado nesse caso, a inserção dos autistas no mercado de trabalho.

A pesquisa contempla a investigação de cinco especialistas de inserção de mercado do trabalho de autistas, cinco empresas que tenham autistas em suas organizações e cinco autistas que estejam inseridos no mercado de trabalho. Estes foram escolhidos por preencherem os requisitos para participar da pesquisa e pela acessibilidade (Rio de Janeiro), respeitando a delimitação do estudo. Por fins éticos, a identidade de nenhum entrevistado será revelada. 


\subsection{Procedimentos e instrumentos de coleta de dados utilizados no estudo}

O instrumento utilizado para a coleta de dados foi a entrevista. De acordo com Rosa e Arnoldi (2006) a entrevista é uma das técnicas de coleta de dados considerada como sendo uma forma racional de conduta do pesquisador, previamente estabelecida, para dirigir com eficácia um conteúdo sistemático de conhecimentos, de maneira mais completa possível, com o mínimo de esforço de tempo. Ribeiro (2008) complementa dizendo que esta é a técnica mais pertinente quando o pesquisador quer obter informações a respeito do seu objeto, que permitam conhecer sobre atitudes, sentimentos e valores subjacentes ao comportamento, o que acaba sendo essencial para este estudo, que procura compreender não somente a inserção dos autistas no mercado de trabalho, mas também as suas relações interpessoais e seus sentimentos neste processo, o que as empresas esperam e percebem destes.

É importante ressaltar que as 15 entrevistas conduzidas foram divididas em 3 grupos:

Grupo 1 - Autistas inseridos no mercado de trabalho.

Grupo 2 - Empresas com autistas em suas organizações.

Grupo 3 - Especialistas no tema.

Esta divisão foi feita para alcançar respostas mais específicas de cada grupo. Além dessa divisão, para cada grupo havia oito perguntas préestabelecidas procurando responder os objetivos do estudo, totalizando em 24 perguntas. As entrevistas foram realizadas no mês de novembro. Com isso, foi possível verificar quais são as diretrizes das empresas para os autistas e se estão disponibilizando as melhores condições para o desenvolvimento destes, as dificuldades que uma pessoa com TEA enfrenta para conseguir um emprego e os desafios do dia-a-dia no trabalho e a importância dada pelos especialistas para os cursos específicos que qualifiquem os autistas ao mercado de trabalho. 


\subsection{Tratamento e análise dos dados coletados para o estudo}

As características dos autistas, as análises dos especialistas e políticas das empresas foram tratadas de forma não estatística, ou seja, de forma qualitativa.

Os dados obtidos foram examinados através da análise de conteúdo, que é uma técnica de tratamento de dados coletados, que visa à interpretação de material de caráter qualitativo, assegurando uma descrição objetiva, sistemática e com a riqueza manifesta no momento da coleta dos mesmos (BARDIN, 2009).

\subsection{Limitações do Método}

O grupo de autistas, empresas, especialistas investigados no estudo é pequeno e por este motivo a pesquisa não traz resposta conclusiva para todos os componentes deste universo, se limitando aos entrevistados deste estudo. Todas as respostas decorrentes das entrevistas representam as opiniões dos entrevistados, não podendo expandir a outros contextos. 


\section{Resultados da pesquisa}

\subsection{Os entrevistados}

Por questões éticas nenhum dos entrevistados terá o nome revelado, sendo assim, foram escolhidos nomes fictícios para um melhor entendimento dos mesmos e do estudo.

Grupo 1 - Este grupo é composto por cinco autistas que estão inseridos no mercado de trabalho na cidade do Rio de Janeiro. João fez 19 anos recentemente e trabalha em uma cafeteria no centro da cidade, Pedro tem 25 anos e atualmente está empregado em uma empresa de TI, o que foi sempre o seu sonho, José de 23 anos conseguiu emprego na padaria do seu bairro graças a seus familiares, Vagner é auxiliar administrativo e tem 25 anos, e Maria tem 32 e também é responsável pela parte administrativa da empresa em que trabalha.

Grupo 2 - Este grupo é composto por cinco empresas situadas no Rio de Janeiro. A Café S.A, Tecnologia da Informação S.A, Administração S.A, Computador S.A e Telecom S.A. As empresas atuam nos segmentos de acordo com seus nomes fictícios.

Grupo 3 - Este grupo é composto por cinco especialistas situados no Rio de Janeiro. Fernanda é especializada em Emprego Apoiado e Inclusão, Renata é psicopedagoga, Jéssica é psicóloga, Paula é neuropediatra e a Luiza também trabalha com Emprego Apoiado e Inclusão.

É importante ressaltar que as cinco são especializadas em indivíduos com Transtorno do Espectro Autista e trabalham exatamente no tema de inserção de mercado de trabalho dos mesmos. 


\subsection{Resposta e análise}

\subsubsection{Grupo 1}

\subsubsection{Especialização da mão-de-obra}

Dos cinco entrevistados do Grupo 1, três relataram que receberam ajuda seja por projeto ou curso de especialização, onde puderam desenvolver habilidades laborais e sociais. É importante ressaltar que $87,5 \%$ dos autistas de alto grau de funcionamento que recebem ajuda para a inserção no mercado de trabalho conseguem emprego. João, que conseguiu o emprego recentemente graças a este tipo de ajuda relata:

"Se hoje tenho um emprego, devo agradecer ao curso de especialização que fiz. Era um projeto voltado para adolescentes e adultos com algum tipo de deficiência que tinham dificuldades para conseguir emprego, ou pelo fato de não receber nenhuma oferta de emprego ou por não ter a capacidade técnica ou social para alguma função. $O$ curso podia te desenvolver em diversas profissões, primeiro viam em qual profissão você tinha mais aptidão e a partir daí continuavam desenvolvendo suas habilidades e na segunda parte aprendemos quais são os comportamentos a serem seguidos na empresa. Depois disso tudo, encaminhavam a gente para empresas que tinham interesse em contar com pessoas como nós."

Essa ponte da adolescência para o mercado de trabalho pode determinar o quão inseridas estas pessoas serão, não somente no mercado de trabalho, mas também na sociedade. Este depoimento do João demonstra a importância do amparo para os autistas, que possuem aptidões a serem exploradas, cabendo ao Estado propor mais criações de cursos como este. 


\subsubsection{Ambiente propiciado pela empresa}

Os autistas possuem características extremamente peculiares, e o que torna mais intrigante é que a forma como se aborda um autista pode variar de indivíduo para indivíduo. Isso se deve pela forma como o TEA se manifesta nos mesmos, fazendo com que seja crucial a capacidade adaptativa da organização para cada pessoa autista, compreendendo que não existe apenas uma maneira correta para se sentirem aceitos e adaptados, mas sim de acordo com cada autista. Pedro relatou o esforço de sua empresa para que se sentisse o mais à vontade possível:

"Desde que cheguei no meu trabalho pude ver o esforço que fizeram para eu me adaptar o mais rápido possível, e isso não só por parte do meu mentor e chefe, mas também pelos meus colegas de trabalho. Tenho muita dificuldade em trabalhar sob pressão, preciso fazer as coisas no meu tempo, então nunca colocam nenhuma data de entrega para mim. O engraçado é que, de acordo com eles, sempre acabo entregando bem rápido as minhas tarefas, algo que acho que não iria acontecer se recebesse algum tipo de pressão"

A empresa do Pedro fez um ótimo trabalho na sua adaptação, não apenas todos da organização procuraram que o mesmo se sentisse em "casa", mas a organização também entendeu que a sua maior dificuldade é com prazos, portanto nunca limitou ele a isso, fazendo com que trabalhasse no seu próprio tempo. Já o relato de Maria foi diferente, contou das dificuldades que passou no antigo emprego:

"Eu estava trabalhando em uma empresa, nas cotas, quando fui desligada justamente por a empresa não respeitar minha maneira de funcionar. Mesmo estando empregada nas cotas como autista não fizeram minha inclusão na empresa, eu não podia nem usar o fone de ouvido para eliminar barulhos que me afetavam o sensorial."

A política de inclusão na empresa já existia, mas não sabia como lidar com um empregado que tivesse necessidades diferentes, falhando na fase da adaptação, trazendo uma péssima experiência para o mesmo e deixando uma imagem ruim para a empresa no que concerne a inclusão. $O$ depoimento de 
Maria reforça a importância da capacidade de se adaptar a novas situações que uma organização deve ter.

\subsubsection{Relação com colegas de trabalho}

O ser humano precisa se sentir incluído para de fato se sentir pertencente a algum grupo na sociedade, e isso não é diferente nos ambientes corporativos. Vagner relatou sobre o seu relacionamento com os seus colegas de trabalho:

"Todos me tratam com respeito e seriedade, nunca senti que alguém fez algo para mim por sentir pena, eles me tratam como se eu fosse uma pessoa normal, e é o que eu sou, uma pessoa que tem um modo diferente de pensar do convencional"

O fato de se sentir parte do grupo faz com que Vagner não tenha dúvidas em relação ao seu potencial, negando qualquer tipo de pensamento de limitação. $O$ relato de José mostra o outro lado disso:

"Apesar de nunca ter sofrido nenhum bullying explícito nunca fui chamado para nenhum tipo de confraternização dos meus colegas. Nas confraternizações da empresa sempre sou convidado, mas quando alguém sai depois do horário de trabalho nunca me chamam para ir junto. Realmente não sei o motivo, nunca tive nenhum tipo de problema de relacionamento com eles, talvez tenham vergonha ou se incomodem que eu mexa a minha cabeça constantemente."

Para José é importante o relacionamento fora da empresa, e isso claramente acaba o incomodando. Talvez nem seja pelo fato dos seus movimentos repetitivos que não o convidem, mas esse é o primeiro motivo que vem na sua cabeça. É sempre importante a mediação da organização para que pessoas como neste caso de José não se sintam mal ou deixadas de lado por conta de sua síndrome. 


\subsubsection{Grupo 2}

\subsubsection{Política de adaptação da empresa}

Das cinco empresas entrevistadas apenas o Café S.A relatou não possuir uma política direcionada para a inclusão dos autistas. Das outras quatro empresas, a que apresentou um processo mais complexo de inclusão foi a Telecom S.A:

"É um longo processo, que não envolve somente o autista, mas também todos os profissionais que entram na empresa. Digamos que você não é autista e acabou de entrar na empresa, você passará por uma série de treinamentos, e um destes treinamentos é celebrar a inclusão e a diversidade, recebendo dicas de como se relacionar e quais dificuldades cada deficiência pode ter, desta forma preparando o profissional a lidar com pessoas com autismo, por exemplo. Em relação ao autista, antes de começar de fato a exercer suas atividades, procuramos saber quais são singularidades, o que pode ajudá-los a se sentirem o mais confortável possível no ambiente de trabalho. O passo seguinte é a designação do chamado conselheiro, que é um colega de trabalho que ajudará no processo de adaptação, tornando-se uma espécie de facilitador para o profissional. E o trabalho não para por aí, pedimos para os gestores que façam relatórios semestrais para a análise de desenvolvimento e de inclusão do profissional, e também um feedback do mesmo, pois é importante sabermos se o que estamos oferecendo é realmente o que ele necessita ou se há a necessidade de adaptação no processo."

A Telecom S.A apresenta um método inclusão bastante interessante, ocorrendo o acompanhamento individual e também a possibilidade de modificação caso algo não esteja indo de acordo com o esperado. É necessário salientar que o Café S.A é a menor das cinco empresas, mas isso não significa que a organização possa estar sem nenhum tipo de direcionamento em relação a inclusão. O objetivo final de qualquer política de inclusão é para que o indivíduo se sinta parte do grupo e que esteja confortável o suficiente para desempenhar suas funções, no caso do Café S.A a gerência precisa analisar se existe algum empecilho para o desempenho pleno da função e tentar junto ao profissional, achar uma forma de pular este obstáculo. 


\subsubsection{Relação do profissional autista no ambiente de trabalho a partir da ótica da organização}

Todas as empresas relataram que os seus profissionais autistas apresentam relação interpessoal adequada para o ambiente, que nunca tiveram nenhum tipo de desavença ou problemas sérios na organização. A Telecom S.A relatou um fato interessante:

"O respeito é mútuo, é uma relação profissional. Algo curioso e raro em um ambiente de trabalho é que ele nunca fez perguntas de cunho pessoal, sempre manteve todas as conversas relacionadas ao trabalho ou assuntos triviais, mas nunca perguntou nada pessoal para nenhum colega."

Muitas vezes o autista pode levar o significado de uma palavra ou situação de forma literal, neste caso não é diferente, muito provavelmente esse profissional aprendeu que o trabalho era um ambiente sério e somente para assuntos relacionados ao mesmo, portanto nunca quis ultrapassar este ponto.

\subsubsection{Avaliação do impacto do profissional autista na organização}

A visão da organização sobre o profissional autista é um fator chave para que mais empresas passem a contar com os mesmos, e as cinco empresas entrevistadas avaliaram o impacto dos autistas como positivo, com destaque para o Café S.A e o Computador S.A. De acordo com o Computador S.A:

'Ela está conosco há mais de dois anos e até hoje ficamos impressionados com o seu raciocínio rápido e acima de tudo preciso. O nosso ambiente demanda rapidez e esta profissional sempre esteve junto ou à frente do prazo determinado, além de ser uma pessoa bem extrovertida. O impacto não poderia ser melhor, tanto na parte de resultados quanto na parte de agregação junto aos seus pares." 
Já o Café S.A relatou que:

"De todos esses anos em que trabalho no Café S.A, ele é o único funcionário que eu nunca vi atender algum cliente de mau humor, pra quem trabalha no mercado de serviço sabe o quão difícil é estar sempre com um sorriso no rosto, mas com ele não, é diferente, ele realmente gosta, tem prazer em atender, servir as pessoas."

São características citadas no referencial teórico que aparecem novamente no depoimento dessas empresas, como a resiliência e a capacidade analítica do autista. É pertinente salientar que cada autista tem a sua aptidão e que a empresa é responsável por saber maximizar estas qualidades, podendo assim ter resultados parecidos como o Café S.A e o Computador S.A.

\subsubsection{Grupo 3}

\subsubsection{Diagnóstico do Transtorno do Espectro Autista}

Um assunto de interesse de todos os autistas e familiares é saber se se está apto a trabalhar, a assumir funções de responsabilidades e ter uma vida independente. A neuropediatra Paula comentou sobre esse tema delicado:

"Antes de cravar se determinado indivíduo pode trabalhar ou não é preciso pensar desde o primeiro momento em que o TEA é diagnosticado e quais são os tratamentos tomados a partir deste momento. É comprovado que quanto mais cedo se diagnostica e começa o tratamento maiores são as chances de desenvolvimento geral do indivíduo, logo as chances de uma vida mais plena aumentam. A síndrome é dividida em graus de severidade, e os autistas com alto grau de funcionamento são capazes de encararem o mercado de trabalho, contudo, existe um grau severo da síndrome que ainda não sabemos como tratálo a ponto de deixar a pessoa apta as diversas atividades do cotidiano."

Mais uma vez é explícito a necessidade de uma política de Estado para conseguir realizar o diagnóstico nos autistas enquanto são crianças, e ir além disso, fornecendo tratamentos multidisciplinares as mesmas para o 
desenvolvimento, permitindo que tenham uma vida mais plena, e em muitos casos chegando a sonhada inserção de mercado de trabalho.

\subsubsection{Acompanhamento do autista ao mercado de trabalho}

Fernanda, que é especialista em Emprego Apoiado e Inclusão, deu a sua visão sobre o tema:

"Considero fundamental o acompanhamento da infância para a adolescência até a fase adulta, pois cada estágio demanda novos estímulos e aprendizados necessários para o desenvolvimento dos autistas. Na infância e adolescência é necessário o acompanhamento pediátrico, psiquiátrico, neurológico e educacional para que cada necessidade seja atendida, e em determinado momento, quando o indivíduo for capaz de exercer diversas tarefas de forma independente, procurar algum tipo de programa que o auxilie, como o Emprego Apoiado, que tem como objetivo incluir pessoas no mercado de trabalho com situação de incapacidade mais insignificativa, respeitando seus interesses, escolhas, pontos fortes e dificuldades. É um programa dividido em três fases: a primeira é descobrir o perfil vocacional do indivíduo, em seguida o desenvolvimento de emprego e depois no acompanhamento pós-colocação."

A presença de programas, projetos, cursos e oficinas é preponderante para o sucesso dos autistas, caso não haja nenhum tipo de auxílio, apenas 6,2\% dos autistas de alto grau de funcionamento conseguem empregos, o que é um número desastroso se for analisado a quantidade de pessoas e mentes brilhantes que podem agregar no nosso mercado de trabalho e são deixados de fora.

\subsubsection{Adequação das empresas}

A psicóloga Jéssica, que atua há mais de 26 anos na área, relatou a sua opinião na importância que as empresas têm na adaptação dos profissionais autistas: 
"Autistas produzem no seu próprio tempo, não no modo que terceiros esperam. Com essa premissa em mente, a organização deve compreender que a imposição de metas e regras devem ser flexíveis para eles, que na maioria dos casos a pressão pode deixá-los ansiosos e cercados, dificultando qualquer tipo de resolução das funções no ambiente organizacional. Não estou dizendo que não devem existir regras ou uma exigência de produtividade, mas tudo se resume na forma em que isso é cobrado, deve ser feito de uma maneira que o profissional autista não se sinta tirado da sua zona de conforto, e isso requer muita habilidade por parte das empresas, não é uma tarefa fácil, pois cada indivíduo autista tem suas próprias necessidades e características".

As empresas precisam ter um feeling diferenciado para conseguir identificar as características do profissional autista e conseguir integrá-lo ao ambiente de trabalho. A cobrança na organização nunca pode deixá-lo acuado, de maneira que não se sinta à vontade para praticar suas atividades, a abordagem deve ser feita de forma delicada e cuidadosa. 


\section{Conclusões e contribuições do estudo}

O autismo ainda é uma grande incógnita no que diz respeito a sua causa ou na existência de um tratamento definitivo, mas existe uma realidade explícita: os deficientes, neste caso os autistas, de forma mais específica, foram excluídos do mercado trabalho. Para que isso não perdurasse a Lei Berenice Piana ( ${ }^{0}$ 12.764) foi criada em 2012, lei esta que passou a considerar o autista deficiente, o que garantiu mais direitos como previsto na Lei Brasileira de Inclusão No 13.146, um destes direitos é que a pessoa com deficiência tem direito ao trabalho de sua livre escolha e aceitação, em ambiente acessível e inclusivo, em igualdade de oportunidade com as demais pessoas. Então não passa a ser somente uma questão ética e moral, mas também legal, onde as empresas devem contratar essas pessoas pelo sistema de cotas e garantir a inclusão.

No referencial teórico, abordou-se que $87,5 \%$ dos autistas com alto grau de funcionamento que receberam suporte para a inserção no mercado de trabalho conseguiram emprego, a importância do acompanhamento dos autistas foi corroborado pela Fernanda, profissional especializada em Emprego Apoiado e Inclusão, onde citou a necessidade do acompanhamento de todas as fases da vida, que é um constante processo de desenvolvimento que culminará na inserção no mercado. João, que é autista e trabalha numa cafeteria, também reforça a importância, dizendo que "Se hoje tenho um emprego, devo agradecer ao curso de especialização que fiz". A ajuda é sim necessária, mas a quantidade atual de organizações para capacitar esses indivíduos é pequena e nem todos possuem o conhecimento desse tipo de trabalho inclusivo. É necessário a criação de uma política efetiva que garanta a inclusão dos autistas no mercado de trabalho, que os meios sejam oferecidos a eles e que tenham a oportunidade de crescer, não basta somente a criação de uma lei que garanta direitos, é imprescindível que ocorra uma ação efetiva por parte do Estado. No Brasil existem cerca de dois milhões de autistas, e se apenas 6,2\% dos autistas com alto grau de funcionamento conseguem empregos, o número de desempregados por conta da falta de auxílio é descomunal.

Além disso, foi possível verificar graças à pesquisa o quão importante é a relação empresa-autista e quais são os passos a se seguir para que haja um 
ambiente harmonioso onde as duas partes saem ganhando. Maria, que é autista e é responsável pela parte administrativa em que trabalha, pôde demonstrar a partir do seu relato o que acontece quando esse ambiente não se torna adaptado para o autista, dizendo "que não respeitaram à sua maneira de funcionar". A peculiaridade de cada indivíduo é um elemento dessa síndrome, tornando um desafio para as organizações o processo de adaptação ao ambiente de trabalho.

Por fim, os relatos dos impactos dos profissionais autistas nas cinco empresas entrevistadas foram considerados positivos, com destaque para 0 Café S.A e Computador S.A, que evidenciaram as capacidades cognitivas e de capacidade de relacionamento dos seus funcionários autistas. As empresas não devem limitar a sua visão sobre os autistas como funcionários que cumprem a cota de autistas, mas sim como pessoas extremamente capazes quando estão em seus termos, podendo gerar vantagem competitiva para a organização.

\subsection{Sugestões}

Seria interessante um estudo mais amplo e profundo sobre a situação dos autistas no mercado de trabalho, não só em âmbito municipal, mas nacional, aliando o método quantitativo às pesquisas para saber o cenário exato dos autistas que procuram uma posição no mercado de trabalho. $O$ aumento do escopo da pesquisa também é válido, indo a fundo nas ações governamentais, para verificar se de fato se estão sendo realizados esforços para melhorar a posição dos autistas no mercado de trabalho.

O número de autistas no Brasil chega na casa dos milhares, e muitos deles não possuem condições para arcar com um tratamento digno que possa prepara-los para a vida, esse papel de provedor passa a ser do Estado, que tem a obrigação de oferecer melhores condições para os autistas. O governo não pode mais dar as costas para esse grave problema que parcela significativa da população enfrenta. É importante ressaltar que atrás de uma pessoa autista existe toda uma família que também encara essa situação e é afetada pelas dificuldades que a síndrome pode apresentar, o amparo além de ajudar os autistas também serve para dar esperança as famílias que tanto lutam pela melhora dos seus parentes com esta síndrome. 


\section{.Referências Bibliográficas}

American Psychiatric Association. Diagnostic and statistical manual of mental disorders. 5th ed. Arlington: American Psychiatric Association; 2013.

AMY, M. D. Enfrentando o autismo: a criança autista, seus pais e a relação terapêutico. Rio de janeiro: Jorge Zahar Ed., 2001.

Autistas a caminho do mercado de trabalho. Oi Educa. Disponível em: http://www.oieduca.com.br/artigos/convivendo-com-a-diferenca/autistas-acaminho-do-mercado-de-trabalho.html?sniveleduca=fam. Acesso em 23/06/2017.

BARDIN L. Análise de conteúdo. Lisboa: Edição 70, 2009.

CARVALHO, R. E. Panorama internacional da integração: Enfoque nacional. Integração, Brasília, v. 5, n. 11, p. 9-13, 1994.

COSTA, Rachel. Autistas chegam ao mercado de trabalho. Revista ISTOE, edição 2191, Disponível em: http://istoe.com.br/174092 AUTISTAS+CHEGAM+AO+MERCADO+DE+TRABA LHO/. 2011. Acesso em 23/06/2017.

COSTA, U. Autismo no brasil: um grande desafio. 1. ed. Rio de Janeiro: Walk Editora, 2013.

FRITH, U. Autism and "Theory of Mind". In C. Gillberg (Ed.), Diagnosis and Treatment of Autism. New York: Plenum Press, 1989.

GIL, A. C. Como elaborar projetos de pesquisa. 4. ed. São Paulo: Atlas, 2008.

KI-MOON, Ban. Secretary-General's message on World Autism Awareness Day. Disponível em: https://www.un.org/sg/en/content/sg/statement/2014-04-02/secretary-generalsmessage-world-autism-awareness-day. 2014. Acesso em 20/09/2017. 
MELO, Luísa. Empresas contratam mais autistas e não é para cotas. Revista Exame, dísponivel em: https://exame.abril.com.br/negocios/empresas-contratammais-autistas-e-nao-e-para-cotas/. 2016. Acesso em 23/06/2017.

MUOTRY, Alysson. Autismo revertido?. Portal G1, disponível em: http://g1.globo.com/platb/espiral/2007/09/21/autismo-revertido/. 2007. Acesso em 29/10/2017.

RIBEIRO, E. A. A perspectiva da entrevista na investigação qualitativa. Evidência: olhares e pesquisa em saberes educacionais, Araxá/MG, n. 04, p.129-148, maio de 2008.

ROSA, M. V. de F. P. , C.; ARNOLDI, M. A. G. C. A Entrevista na pesquisa qualitativa: mecanismo para validação dos resultados. Belo Horizonte: Autêntica, 2006.

SALOMON, D. V. Como fazer uma monografia. 10. ed. São Paulo: Martins Fontes, 2001. p. 91-120.

SIGMAN, M.D et al. Responses to the negative emotions of others by autistic, mentally retarded, and normal children. Child Development, 1992.

SOLOMON, A. Longe da árvore pais e filhos em busca de identidade. 1. ed. São Paulo: Cia. das Letras, 2013.

THOMAS, David A. ELY, Robin A. Making Differences Matter: A New Paradigm for Managing Diversity. Harvard Business Review on Managing Diversity. Boston: Harvard Business School Press, 2002.

TV ANHANGUERA. Mãe pede ajuda para tratamento de filho de $\mathbf{3}$ anos que tem autismo. Portal G1, disponível em: http://g1 .globo.com/goias/noticia/2014/02/pais-tentam-conseguir-tratamentopara-filho-autista-em-porangatu-go.html. 2014. Acesso em 20/09/2017.

VERGARA, S. C. Projetos e relatórios de pesquisa em administração. 3. ed. São Paulo: Atlas, 2000. 
YIN, R. K. Estudo de caso - planejamento e métodos. (2Ed.). Porto Alegre: Bookman. 2001.

ZIKMUND, W. G. Business research methods. 5.ed. Fort Worth, TX: Dryden, 2000. 


\section{Anexo 1}

\section{Roteiro das entrevistas}

\section{GRUPO 1}

1) Qual é o seu diagnóstico no Transtorno do Espectro Autista (TEA)?

2) Com que idade foi diagnosticado?

3) A escola que frequentava era especializada para TEA ou comum?

4) Fez algum tipo de tratamento para a síndrome? Caso a resposta for sim citar e descrever o(s) tratamento(s).

5) Em algum momento participou de algum curso, oficina que tivesse como objetivo te colocar no mercado de trabalho? Caso resposta for sim citar e descrever o(s) curso(s) e oficina(s).

6) Ao procurar emprego, já sofreu algum tipo de preconceito ao dizer que é autista? Caso resposta for sim citar e descrever a situação.

7) Como conseguiu o seu atual emprego?

8) Como é a sua relação com os colegas de trabalho?

\section{GRUPO 2}

1) Qual a área de atuação da empresa?

2) A empresa possui alguma política para empregar deficientes? Caso a resposta for sim descrevê-la.

3) Qual é a razão (proporção) de não deficientes/deficientes?

4) Ao empregar um autista, existe algum tipo de processo para adapta-lo ao ambiente de trabalho? Caso a resposta for sim citar e descrever qual(ais).

5) Como a empresa avalia a relação do profissional autista com os colegas de trabalho?

6) Quais são as características mais positivas do profissional autista?

7) Quais são as maiores dificuldades do profissional autista? 
8) Ao fazer um balanço do profissional autista, como a empresa avalia o impacto deste na organização?

\section{GRUPO 3}

1) Qual é a sua formação?

2) Há quanto tempo trabalha com pessoas com Transtorno do Espectro Autista (TEA)?

3) Qual a importância do autista começar o tratamento multidisciplinar a partir do momento que recebe o diagnóstico?

4) Todas as pessoas diagnosticadas com TEA podem trabalhar?

5) Considera fundamental para que o autista entre no mercado de trabalho um curso especializado?

6) Quais são as características do autista que o torna um bom profissional?

7) Quais são as maiores dificuldades do profissional autista?

8) Quais medidas a empresa deve tomar para a adaptação do profissional autista? 